\title{
Transcription conventions
}

The following are some of the conventions used in data transcripts.

Otherwise, refer to original source:

Language contrast Kinyarwanda

French

(.)

Other language

[

Pause (with or without measured length)

((laughter))

Overlapping talk

(unclear)

Bold

Non-verbal action

With or without transcriber's best guess

Saucissons- yewe waje Recycle / restart

\{first name\}

Target element

Free English translation in a separate sequence after the original.

Letters of the alphabet (A, B, C, etc.) are used for participants so as to preserve their anonymity; where appropriate, $\mathrm{P}, \mathrm{D}$ and Ch specifically represent 'patient', 'doctor' and 'child', respectively. 
